\title{
O Epidemiologista e os Serviços de Saúde Coletiva no Brasil
}

\author{
Luis David Castiel*
}

Apresenta-se uma análise da situação da prática da epidemiologia nos Serviços de Saúde Coletiva. São discutidos aspectos referentes à formação do epidemilogista e às limitaçóes quanto à utilização mais ampla das técnicas epidemiológicas. Por fim, é utilizado um modelo explicativo do processo saúde-doença para orientar a atuação do epidemiologista.

\section{O PANORAMA}

Para abordar-se a situação dos epidemiologistas nos Serviços de Saúde Coletiva cabem três indagações preliminares, todas interligadas:

1) Faz-se que epidemiologia nos Serviços de Saúde?;

2) Qual é a qualidade dessa epidemiologia, ou seja em que medida atinge seus propósitos?;

3) Quais são os possíveis fatores determinantes das questōes anteriores, isto é por que a epidemiologia feita possui tal qualidadc?

Para buscar encaminhamentos a tais indagações, temos de partir de al guma definição de epidemiologia. A Associação Internacional de Epidemiologia produziu no seu Dicionário de Epidemiologia uma definição que parece servir ao nosso intento: $O$ estudo da distribuição e dos determinantes dos estados relacionados à saúde e eventos em populaçóes, e aplicaçāo deste estudo para o controle dos problemas de Saúde (2). Nela está incluída a conhecida divisão entre epidemiologia descritiva e analítica. Mas, também, a idéia da aplicação destes conhecimentos no controle dos problemas de Saúde que ocorrem nas populaçōes. Sob este ângulo, é possível perceber que a epidemiologia desenvolvida nos nossos Serviços de Saúde tende, em geral, a concentrar-se, em especial, na coleta, registro, consolidação, análise e divulgação de dados sobre a ocorrência de doenças transmissíveis assim como na organização e consecução de campanhas de vacinação. A investigação de casos suspeitos de doenças transmissíveis não costuma ser uma prática constante.

Via de regra, não se utiliza o instrumental epidemiológico para determinações mais apuradas que sir* Professor assistente da ENSPI FIOCRUZ

Cadernos de Saúde Pública, RJ, 5 (1): 17-23, jan/mar, 1989 
vam ao planejamento de ações de saúde. Por exemplo: a utilização do Enfoque de Risco, ou entáo técnicas de avaliação de serviços e programas de saúde.

Neste momento, vale a pena Jeter-se na precária qualidade das informaçōes empregadas na Vigilância Epidemiológica. Sabe-se que o sub-registro é considerável para todas as doenças sob vigilância $e$, além disso, não se conhece o grau de confiabilidade dos dados obtidos. Em geral, pode-se pensar que a vigilância epidemiológica dedica-se basicamente à tentativa de monitoraçāo, através de dados precários, da situação de morbi-mortalidade por doenças transmissíveis. Ou seja, tenta-se implementar medidas de controle (que, com exceção das campanhas de vacinação, não costumam ser avaliadas em sua efetividade), sem que haja um conhecimento mais preciso da distribuição das doenças. Isto é até compreensível, pois não se necessitam de dados apurados (no sentido de apuro) para se ter noção do atual panorama epidemiológico das populações: ocorrência considerável de doenças infecto-contagiosas agudas e crônicas, com o recrudescimento de doenças endêmicas e o ressurgimento de doenças que náo ocorriam no nosso meio ou que se tomam epidêmicas em função de catástrofes (dengue, leptospirose). Assim, tudo é tão prioritário, que qualquer que seja o ponto de abordagem, acaba-se acertando em algo que mereça atenção.

Esta configuração reflete o padrão com que são tratados os serviços públicos para as áreas consideradas sociais: carência de recursos, limitaçōes organizacionais, despreparo técnico e inexistência de uma política de saúde consistente o suficiente a ponto de ser efetivada. Se encararmos retrospectivamente o resultado dos planos e propostas da última década, temos: o PIASS, O PREV-Saúde, o plano do CONASP até chegar-se à VIII Conferência de Saúde. Percebe-se que a tendência das propostas é ficarem reduzidas ao nivel das intençōes, numa retórica esvaziada, sem atingir graus mínimos de implantação. Cabe, então, perguntar, qual seria a possibilidade da Reforma Sanitárial SUDS vingar?

É evidente que existem diferenças conjunturais em relação à época dos planos anteriores. Mas, o atual quadro político-econômico geral e, em especial, os rumos do Setor Saúde são de difícil prognóstico. Mesmo com as propostas incluídas na nova Constituição, nāo há sinais sugestivos de que a Reforma Sanitária se estabeleça de modo efetivo e satisfatório.

Se prevalecer o modelo que vem sendo empregado nos últimos anos, o planejamento das açōes de saúde vai prosseguir prescindindo de informaçōes mais precisas e elaboradas. Se assim for, os recursos do Setor Saúde continuaráo a ser dimensionados e alocados aos 
serviços e programas sem deter-se no que se refere ao perfil de morbi-mortalidade da população. Desta forma, não haveria necessidade de melhorar as condiçōes para se atingir maior qualidade da informação. Isto implicaria uma maior inversāo de recursos e a modificação da racionalidade dos processos decisórios. Diante da severa crise econômica (com um considerável déficit público) e da insegura perspectiva que um projeto político com ênfase social tem de se estabelecer, parece haver pouca possibilidade de mudanças substantivas. Assim, as propostas de maior ênfase nas atividades que busquem a determinação das necessidades em saúde das populaçōes devem continuar dando lugar ao planejamento baseado na oferta (precária) de serviços e programas de saúde.

\section{A FORMAÇÃO E A SITUAÇÃO ATUAL DOS EPIDEMIOLOGISTAS NOS ŞERVIÇOS DE SAÚDE}

Se aproveitarmos a definição de epidemiologia, apresentada no início deste texto, o epidemiologista será um profissional que estuda a ocorrência da doença ou outras condiçōes ou eventos relacionados à saúde em populaçōes delimitadas. Inclui-se, também, entre as tarefas do epidemiologista, o controle das doenças nas populaçōes (2). Em geral para intitular-se epide. miologista, deve-se ter freqüentado algum curso de especialização em Saúde Pública e estar localizado em serviços de controle de doenças do setor público ou, então, em departamentos de instituiçōes acadêmicas (após ter-se obtido titulaçōes em cursos de pós-graduação). São estas instituiçōes que costumam dedicarse ao treinamento e capacitação de técnicos para atuarem nos serviços de controle de doenças. No entanto, qual seria 0 alcance e efetividade deste treinamento, uma vez que a epidemiologia desen volvida nos serviços de saúde sofre considerável grau de limitaçōes (recursos, organizacionais, político-administrativas)? Assumiu-se, em passado recente, que a função primordial da academia seria a de estimular a postura crítica dos epidemiologistas em relação aos determinantes político-ideológicos da situação de saúde e da estrutura dos serviços. Parece que esta ênfase estaria sendo modificada. No entanto, diante do complexo quadro descrito anteriormente, qual deve ser, entaao, a proposta conseqüente de formação de epidemiologistas para os Serviços de Saúde? O aparente efeito da ênfase na postura crítica pode ser observado pelo desempenho de técnicos treinados sob esta ótica que se inseriram nos serviços. A impressão que se dispōe é que, em geral, parece haver um descompasso entre o preparo instrumental (que, a bem da verdade, não seria imprescindível para o desempenho das atividades rotineiras

Cadernos de Saúde Pública, RJ, 5 (1): 17-23, jan/mar, 1989 
dos serviços) e a aguçada percepção dos determinantes do processo saúde-doença. Esta aparente distorção viria a indicar tanto as limitaçōes dos serviços como a inadequação da formação de profissionais para esses serviços, para os quais não se requer treinamentos elaborados - não há necessidade de se dominar conteúdos envolvendo estudos analíticos, inquéritos, estudos avaliativos, nem o conhecimento de instrumental estatístico - probabilidades, testes de hipótese... Tais conteúdos estão dissociados da prática dos serviços, ou melhor dizendo, a prática está dissociada da necessidade de se utilizar instrumentos que abordem, com maior efetividade, os problemas de saúde da população.

Além disso, cabe acrescentar mais um aspecto importante a este quadro: o epidemiologista nos Serviços de Saúde é um funcionário público. Isto sigrifíca baixos salários e a conseqüente insatisfação, conduzindo, por vezes a uma postura cínica compartilhada por dirigentes e funcionários e que pode ser resumida na proposta: Vocês fingem que me pagam e eu finjo que trabalho, com danosos efeitos em termos de comprometimento e desempenho. Daí, ter-se a idéia generalizada da forma parasitária com que são encarados os servidores públicos. E claro que, dentre as razões para esta situação, encontra-se o empreguismo que orienta as contratações do funcionalismo público. Desde há muito tempo, sabe-se que o setor público sofre os efeitos perversos da política clientelista, onde os serviços costumam servir de cabides de emprego, fonte de benesses e nepotismo. Com isso, os serviços tendem a apresentar excesso de pessoal, em geral despreparado e desmotivado para o trabalho.

Por outro lado, ser funcionário público significa estar sujeito às contingências geradas pelo funcionamento da máquina administrativa. Neste caso, nota-se que os efeitos dos confrontos político-partidários interferem num grau além do desejável. Emperramentos gerenciais e administrativos podem ser atribuídos a conflitos entre membros de agremiações partidárias rivais. Além disso, ao sabor das mudanças de govemo, têm-se modificaçōes nos quadros dirigentes, provocando dificuldades quanto à continuidade no gerenciamento de serviços e programas.

Em geral, os grupos que ocupam o poder estadual empenham-se em sustentar suas posiçốes (e cargos) sempre passíveis de ameaça diante das iminentes atribulaçōes das configuraçōes políticas estaduais. Desta forma, é possível que, para manter suas posições (e cargos), o atendimento das necessidades e demandas sociais das populações seja negligenciado. Evitam-se enfrentamentos de forças e interesses que tragam desgaste político.

Cadernos de Saúde Pública, RJ, 5 (1): 17-23, jan/mar, 1989 
Esta situação traz flagrantes limitações aos serviços. Não se consegue estabelecer e implementar qualquer política de saúde que nāo seja a de permanecer no status quo. $\mathrm{O}$ que significa continuar numa proposta de atençăo precária à saúde, pois é considerável o poder inercial do quadro existente.

\section{A SAÍDA?}

É evidente que não se ambiciona trazer soluções para problemas estuturais da organização político-administrativa das instituições de saúde. Mas, é preciso ter em mente que tais problemas interferem substancialmente na prática dentro de cada setor e departamento das Secretarias de Saúde.

Dentro do contexto descrito, é difícil uma proposta de mudança amplamente satisfatória. O que se pode fazer é, diante deste quadro, sugerir um encaminhamento mais realista e que nāo negligencie os fatores complicadores.

Uma possibilidade é utilizar o modelo de explicação do processo saúde-doença sugerido por Castellanos como referência. Apesar de críticas quanto aos critérios de definição dos níveis, é possível utilizá-lo para identificar as formas de atuação do epidemiologista conforme a dimensão correspondente. Em linhas gerais, este autor utiliza três categorias de explicação:

A SINGULAR: que ocorre entre indivíduos ou entre agrupaçōes de população; a PARTICULAR: que sucede entre grupos sociais numa mesma sociedade e num mesmo momento dado; e a GERAL: que corresponde à sociedade em geral. Para os propósitos deste texto, vamos enfocar os dois primeiros níveis:

No espaço SINGULAR, o autor indica como sendo a "EPIDEMIOLOGIA DO QUÊ": Os problemas de saúde-doença nesta categoria aparecem como variaçōes entre indivíduos ou atributos individuais; $e$ a forma habitual de definição dos mesmos é a freqüência e a gravidade de uma patologia ou acidente em particular, entre pessoas com determinados atributos de tempo, espaço ou características biológicas ou sociais individuais(1). As Leis e princípios utilizados pela Epidemiologia neste nível relacionam-se com variaçôes de agentes, hospedeiros e dos riscos. Conforme o citado autor, é neste espaço que se localiza a maior parte dos desenvolvimentos teórico-metodológicos $e$ técnicos da epidemiologia para estudar epidemias, para civaliar fatores de risco, para a vigilância de problemas específicos e para a avaliação de tecnologias (1).

No espaço do PARTICULAR, teríamos a "EPIDEMIOLOGIA DE QUEM". Ou seja Os problemas aparecem definidos como variações do perfil de saúdedoença ao nível de grupos da população. A explicação

Cadernos de Saúde Pública, RJ, 5 (1): 17-23, jan/mar, 1989 
enfatiza nos processos de reprodução social das condiçôes objetivas de existência (qualidade de vida) de cada grupo, e nas leis e princípios que regem as acumulações, as formas como se organizam os diferentes momentos de tal processo (...). Abordar os problemas de saúde a este nivel permite identificar as acumulaçōes que produzem o perfil de saúde-doença de cada grupo (1). Permite ainda identificar as açöes a nivel biológico (...), ecológico (...), das formas de consciência e conduta (...) e a nível das relações econômicas que temos possibilidade de modificar (...)(1). As ações de saúde neste nível tendem a dirigir-se para planos e programas de saúde por grupos da população (...) (1). Fica claro, que, neste nível, a atuação dos serviços de saúde fica obstaculizada pelos determinantes sociais da doença - pela própria forma patogênica como a formação sócio-econômica se organiza e articula os serviços para lidar com as patologias originadas pela própria estrutura dessa formaçāo sócio-econômica. De qualquer modo, esta abordagem dá oportunidade de se avaliar o alcance das açōes definidas no nível singular e conceber práticas de atuaçāo para modificar as condições de existência dos grupos excluídos do processo político-social. Enfim, alterar as relações de poder no interior da estrutura social.

Mas, deve ser enfatizado que o en foque PARTICULAR da epidemiologia não exclui absolutamente a dimensão SÎNGULAR. Desta forma, na formação de epidemiologistas, há necessidade do domínio do instrumental epidemiológico para a atuação conseqüente no nível SINGULAR, ao mesmo tempo que, conforme a imagem-objetivo da organizaçāo social que se almeja atingir, agir politicamente para que a proposta da epidemiologia no nível PARTICULAR possa ser implantada.

Em suma, é preciso não negligenciar a competência instrumental ao se abordar os sérios problemas epidemiológicos da nossa realidade. As limitações impostas pela estrutura dos serviços e pela atual racionalidade do planejamento das ações de saúde e alocação de recursos significa que o papel da epidemiologia está sendo, basicamente, o de executar um acompanhamento grosseiro da morbi-mortalidade por doenças infecto-contagiosas. Possivelmente, para detectar situaçōes que se tomem absolutamente graves e somente assim dignas de atenção e, portanto, merecedoras de recursos adicionais.

Porém, os epidemiologistas vinculados aos serviços nâo podem se limitar a dominar apenas conteúdos epidemiológicos e estatísticos restritos. Com um melhor preparo instrumental, teriam maiores condições de indicar as falhas deste modelo e apontar para enca- 
minhamentos mais realistas para a superação de tais falhas no nível SINGULAR.

É evidente a necessidade concomitante de não descurar das questōes na categoria PARTICULAR. Mas, para isto é preciso discenir as formas e os níveis de atuação dentro e fora do setor saúde, na busca de viabilização de propostas de intervenção em determinantes estruturais do processo saúde/doença. Desta forma, é necessário:

1) o entendimento de fatores localizados em níveis de organizaçăo distintos - sejam conjunturais, sejam estruturais.

2) as vias de acesso disponíveis a tais fatores;

3) caso existam tais vias, as possíveis formas de abordá-las. Neste processo, o domínio do instrumental epidemiológico vai permitir especificar tanto o alcance e a efetividade das propostas de intervenção na situação de saúde como os níveis de atuação on de devem ser concentrados os esforços para modificações desta realidade.

The paper analyses the current epidemiological practices and procedures adopted in Brazilian public health services. Selected topics, as the training of epidemiologists and the adverse conditions that prevent a wider utilization of sound epidemiological techniques are discussed. A model ilustrating the health-disease process is offered, as an aid to epidemiologists.

\section{REFERÊNCIAS BIBLIOGÁFICAS}

1. CASTELLANOS, P. Sobre el concepto de Salud - Enfermedad: un punto de vista epidemiológico. Documento apresentado no $\checkmark$ Congreso Mundial de Medicina Social Medellin, Colombia, Julio, 1987.

2. LAST, J. (ed) A Dictionary of Epidemiology.Oxford University Press. London, 1983. 